\title{
CORRELATION BETWEEN LEFT ATRIUM VOLUME INDEX IN TRANS-THORATHIC ECHOCARDIOGRAPHY AND LEFT ATRIUM APPENDAGE THROMBUS IN TRANS- ESOPHAGEAL ECHOCARDIOGRAPHY IN PATIENTS WITH NON-VALVULAR ATRIAL FIBRILLATION
}

\author{
By
Mohamed M. Mansour, Mohamed Sami Abd El-Samea and Sami Hasan INouh \\ Department of Cardiology, Faculty of Medicine, Al-Azhar University, Cairo, Egypt \\ Corresponding author: Mohamed Maged Mansour, \\ E-mail: drmohamedmaged2020@gmail.com
}

\begin{abstract}
Background: Large Left atrium (LA) volume has been associated with adverse cardiovascular outcomes in patients with sinus rhythm and atrial fibrillation (AF).

Objective: To evaluate the accuracy of left atrial (LA) indexed and non-indexed volume to predict transesophageal echocardiographic (TEE) left atrial appendage (LAA) thrombus.

Patients and Methods: This was a cross-sectional study which included 30 patients with non-valvular atrial fibrillation (AF) admitted to Cardiology Department or referred to transthoracic and transesophageal echocardiography (TTE and TEE) from outpatient cardiology clinic at Al-Hussien University Hospital, AlAzhar University, Cairo, Egypt, from February 2020 to October 2020. LA volume was measured on TTE by several methods including LA volume in four and two apical chamber views. All measures were indexed to the body surface area (BSA).

Results: There was a statistically significant increase in indexed and non-indexed LA volume in patients with LAA thrombus compared to patients without LAA thrombus. According to ROC curve, the study found that indexed LA biplane volume was predictive for LAA thrombus with with cutoff $52.2 \mathrm{ml} / \mathrm{m} 2$ (AUC 0.89 , $\mathrm{p}<0.007)$.

Conclusion: Large LA volume was suitable to predict LAA thrombus in patients with non- valvular AF.

Keywords: Non-valvular atrial fibrillation; Left atrial volume; LAA thrombus; transthoracic echocardiography; Transesophageal echocardiography.

\section{INTRODUCTION}

Enlargement of left atrium (LA) has been established as a prognostic marker for adverse CV outcomes such as atrial

fibrillation, stroke, congestive heart failure, and cardiovascular death. Different methods exist for the assessment of LA size. The American Society of Echocardiography recommended LA
\end{abstract}


volume and its indexed value assessed by 2-dimensional echocardiography to measure LA size. The pathogenesis of LAA thrombus results from stagnation within the long, blind ended trabeculated pouch. Diminished contractility of the appendage leads to reduction in blood flow as well. LAA thrombus is associated with a large LAA area. The prevalence of LA/LAA thrombi gradually increases with the number of clinical risk factors. The LAA is the site most commonly associated with thrombus formation, particularly in patients with nonvalvular AF. Larger LA and LAA sizes are associated with lower LAA flow velocity and risk of ischemic stroke. Transesophageal echocardiography (TEE) is sensitive in the assessment of parameters associated with thromboembolism including thrombus in the LA appendage (LAA thrombus), dense spontaneous echocardiographic contrast (SEC), low LA appendage flow velocities (low LAA velocities) (Providência et al., 2011).

The presence of at least one of the three previous TEE changes has been associated with a risk of stroke of $7.8 \%$ a year. TEE is the most sensitive and specific technique to detect LAA thrombus in patients with $\mathrm{AF}$ prior to cardioversion. However, several studies demonstrated that LAA is free of thrombi in $86 \%$ of $\mathrm{AF}$ patients who underwent a TEE prior to cardioversion. The cost implications of this practice are particularly important because TEE is an increasingly utilized procedure, (GarnockJones et al., 2010).

In addition to the associated risk of complications such as oral and esophageal trauma and the risks of conscious sedation. Therefore, there may be a role for risk stratification in patients with $\mathrm{AF}$ to determine the need for a TEE to exclude the presence of LAA thrombus prior to cardioversion.

The present work aimed to evaluate the accuracy of left atrial (LA) indexed and non-indexed volume to predict transesophageal echocardiographic (TEE) left atrial appendage (LAA) thrombus.

\section{PATIENTS AND METHODS}

This is a cross-sectional study which included 30 patients with non-valvular atrial fibrillation (AF) admitted to Cardiology Department or referred to transthoracic and transesophageal echocardiography (TTE and TEE) from outpatient cardiology clinic in Al-Hussien University Hospital, Al-Azhar University, Cairo, Egypt from February 2020 to October 2020. LA volume was measured on TTE by several methods including LA volume in four and two apical chamber views. All measures were indexed to the body surface area (BSA).

Inclusion criteria: All patients with first diagnosed non-valvular atrial fibrillation recent, paroxysmal or persistent $\mathrm{AF}$ suitable for cardioversion.

Exclusion criteria: Patients with any of the following criteria were excluded from the study:

1. Patients with moderate or severe mitral stenosis, severe mitral regurgitation.

2. Patients with moderate or severe aortic stenosis.

3. Patients with hemodynamic instability necessity use of positive inotropes. 
4. Patients with prosthetic mitral or aortic valves.

5. Patients with unsuitable images for accurate assessment of transthoracic echocardiography

measurements or transesophageal echocardiography (TEE) markers of thromboembolic risk.

6. Patients with any contraindication to TEE.

Patients who met the inclusion criteria were subjected to the following:

\section{Thorough history taking.}

2. Full clinical examination: Targeted physical examination data were recorded including general and local examination with special attention to vital data and signs suggestive of risk factor for $\mathrm{AF}$ and calculated body surface area (BSA), body mass index (BMI) and CHA2DS2-VASc scores (Lip et al., 2010).

3. Laboratory examination including international normalized ratio (INR), creatinine and glomerular filtration rate (GFR).

4. Twelve-leads surface ECG was performed on presentation, before TTE and TEE and before and after cardioversion.

\section{Transthoracic echocardiography:} All patients underwent Doppler echocardiographic examination using a commercially available system (GE). Examinations performed by three trained echo cardiographers according to American Society of Echocardiography. M-mode, color Doppler and two- dimensional transthoracic images used to obtain the following measurements:

a. Left atrium anteroposterior diameter (LA AP).

b. Left atrium (LA) area.

c. Indexed and non-indexed LA volumes by four and two apical views and biplane.

d. The left ventricular end-systolic dimension (LVESD) and end diastolic dimension (LVEDD) were obtained from M-mode recording, from the parasternal long axis view. The LV ejection fraction (LVEF) was estimated by M-mode in para strenal long axis view.

e. The 16-segment model for LV segmentation was used to evaluate regional wall motion abnormalities as recommended by the American Society of Echocardiography.

f. Color doppler imaging was acquired from the apical four, two and three chamber views on mitral and aortic valves.

6. Transesophageal echocardiography: TEE images showed LA and LA appendage (LAA) in different tomographic planes and detected the presence of LAA thrombus which was diagnosed by the presence of an echo dense mass in the left atrium or the LAA.

\section{Statistical analysis:}

Data were analyzed using Statistical Package for the Social Sciences (SPSS) version 20. Quantitative data were expressed as mean \pm standard deviation (SD) and range. Qualitative data were 
expressed as frequency and percentage. Independent t-test or Mnn-whitney $\mathrm{U}$ test were used to compare means. Chi-square test was used to compare percentages.
ROC curve was plotted to get cutoff value. A $p$ value of $<0.05$ was considered significant.

\section{RESULTS}

The mean of age \pm SD was $60.47 \pm$ 9.220 years. They were 9 females $(30 \%)$ and 21 patients were males $(70 \%), 26$ of them were hypertensive $(86.7 \%), 9$ diabetic $(30 \%), 19$ smokers $(63.3 \%), 5$ patients had history of stroke and/or TIA (16.7\%). All patients were diagnosed as having AF for the first time.
The basic characteristics of the studied patients showed duration of AF was 2.53 \pm 2.1 , age was $60.47 \pm 9.22$ years, CHA2DS2-VASc Score was 2.6 \pm 1.77 , weight was $76.87 \pm 8.39 \mathrm{~kg}$, height was $172.63 \pm 5.91 \mathrm{~cm}$, and body mass index was $25.88 \pm 3.35 \mathrm{~kg} / \mathrm{m} 2$ (Table 1).

Table (1): Analysis of basic characteristic of studied patients

\begin{tabular}{|c|c|c|}
\hline \multicolumn{2}{|c|}{ Basic Characteristic } & Patients $(\mathbf{n}=\mathbf{3 0})$ \\
\hline \multirow{2}{*}{ Age } & Mean \pm SD & $60.47 \pm 9.22$ \\
\cline { 2 - 3 } & Range & $38-73$ \\
\hline \multirow{2}{*}{ Duration of AF } & Mean \pm SD & $2.53 \pm 2.1$ \\
\cline { 2 - 3 } & Range & $0-8$ \\
\hline CHA2DS2-VASc & Mean \pm SD & $2.6 \pm 1.77$ \\
\cline { 2 - 3 } Score & Range & $0-6$ \\
\hline \multirow{2}{*}{ Height } & Mean \pm SD & $172.63 \pm 5.91$ \\
\cline { 2 - 3 } & Range & $157-181$ \\
\hline \multirow{2}{*}{ Weight } & Mean \pm SD & $76.87 \pm 8.39$ \\
\cline { 2 - 3 } & Range & $65-95$ \\
\hline \multirow{2}{*}{ BMI } & Mean \pm SD & $25.88 \pm 2.35$ \\
\cline { 2 - 3 } & Range & $21-34$ \\
\hline
\end{tabular}

The laboratory findings of the studied patients showed serum creatinine was 1.35 \pm 0.52 , INR was $1.13 \pm 0.22$, and GFR was $70.74 \pm 31.93$ (Table 2).

Table (2): Analysis of Laboratory findings of studied patients

\begin{tabular}{|c|c|c|}
\hline \multirow{2}{*}{ Laboratory findings } & Patients $(\mathbf{n}=\mathbf{3 0})$ \\
\hline \multirow{2}{*}{ Creatinine } & Mean \pm SD & $1.35 \pm 0.52$ \\
\cline { 2 - 3 } & Range & $1-3$ \\
\hline \multirow{2}{*}{ INR } & Mean \pm SD & $1.13 \pm 0.22$ \\
\cline { 2 - 3 } & Range & $1-2$ \\
\hline \multirow{2}{*}{ GFR } & Mean \pm SD & $70.74 \pm 31.93$ \\
\cline { 2 - 3 } & Range & $23-140$ \\
\hline
\end{tabular}


The 2D TTE findings of the studied patients showed LVEDD was 52.8 \pm 4.8 , LVESD was $36.1 \pm 7.2$, LVEDV was $135.42 \pm 26.89$, LVESV was $57.94 \pm$ 27.94 , EF was $58.93 \pm 13.13$, LA diameter was $4.25 \pm 0.49$, LA length four chamber view (A4) was $5.62 \pm 0.83$, LA area A4 was $24.55 \pm 6.52$, LA volume A4 was
$83.08 \pm 41.51$, LA volume index A4 was $43.55 \pm 21.73$, LA length two chamber view (A2) was $5.51 \pm 0.99$, LA area A2 was $24.54 \pm 5.01$, LA volume A2 was $84.28 \pm 30.57$, LA volume index A2 was $42.63 \pm 18.05$, LA volume biplane was $86.16 \pm 38.15$, and LA volume index biplane was $45.22 \pm 20.57$ (Table 3).

Table (3): Analysis of echocardiographic parameters of studied patients

\begin{tabular}{|c|c|c|}
\hline \multicolumn{2}{|c|}{ Echocardiographic parameters } & Patients $(n=30)$ \\
\hline \multirow{2}{*}{ LA diameter $(\mathrm{cm})$} & Mean \pm SD & $42.5 \pm 4.9$ \\
\hline & Range & $37-53$ \\
\hline \multirow{2}{*}{$\mathrm{LV} \operatorname{EDD}(\mathrm{mm})$} & Mean \pm SD & $52.8 \pm 4.8$ \\
\hline & Range & $44-62$ \\
\hline \multirow{2}{*}{ LV ESD $(\mathrm{mm})$} & Mean \pm SD & $36.1 \pm 7.2$ \\
\hline & Range & $24-51$ \\
\hline \multirow{2}{*}{ LV EDV (ml) } & Mean \pm SD & $135.42 \pm 26.89$ \\
\hline & Range & $62-187$ \\
\hline \multirow{2}{*}{ LV ESV (ml) } & Mean \pm SD & $57.94 \pm 27.94$ \\
\hline & Range & $16-124$ \\
\hline \multirow{2}{*}{ LV EF (\%) } & Mean \pm SD & $58.93 \pm 13.13$ \\
\hline & Range & $32-75$ \\
\hline \multirow{2}{*}{ LA length A4(mm) } & Mean \pm SD & $56.2 \pm 8.3$ \\
\hline & Range & $39-81$ \\
\hline \multirow{2}{*}{$\mathrm{LA}$ area $\mathrm{A} 4(\mathrm{~cm} 2)$} & Mean \pm SD & $24.55 \pm 6.52$ \\
\hline & Range & $14-39$ \\
\hline \multirow{2}{*}{ LA volume A4 } & Mean \pm SD & $83.08 \pm 41.51$ \\
\hline & Range & $31-210$ \\
\hline \multirow{2}{*}{ LA volume index A4 } & Mean \pm SD & $43.55 \pm 21.73$ \\
\hline & Range & $18-107$ \\
\hline \multirow{2}{*}{ LA length A2 } & Mean \pm SD & $55.1 \pm 9.9$ \\
\hline & Range & $37-87$ \\
\hline \multirow{2}{*}{ LA area $\mathrm{A} 2$} & Mean \pm SD & $24.54 \pm 5.01$ \\
\hline & Range & $15-38$ \\
\hline \multirow{2}{*}{ LA volume A2 } & Mean \pm SD & $84.28 \pm 30.57$ \\
\hline & Range & $36-173$ \\
\hline \multirow{2}{*}{ LA volume indexA2 } & Mean \pm SD & $42.63 \pm 18.05$ \\
\hline & Range & $7-98$ \\
\hline \multirow{2}{*}{ LA biplane volume } & Mean \pm SD & $86.16 \pm 38.15$ \\
\hline & Range & $40-198$ \\
\hline \multirow{2}{*}{$\begin{array}{l}\text { LA biplane volume } \\
\text { index }\end{array}$} & Mean \pm SD & $45.22 \pm 20.57$ \\
\hline & Range & $20.3-105.9$ \\
\hline
\end{tabular}


According to LAA appendage assessment by TEE, patients were classified into two groups: Group $1(\mathrm{n}=5)$ had LAA thrombus, and Group $2(\mathrm{n}=25)$ had no LAA thrombus. By analysis and comparison of collected data, there were no statistically significant difference in terms of Age ( $\mathrm{P}$ value 0.057), gender ( $\mathrm{P}$ value 0.593), diabetes mellitus (DM) $(\mathrm{P}$ value $=0.109)$, hypertension $(\mathrm{HTN})(\mathrm{P}$ value 0.631 ) and smoking (P value 0.865$)$, while history of stroke/TIA was had statistically significant difference $(\mathrm{P}$ value $<0.001$ ) (Table 4).

Table (4): Comparison of risk factors of studied patients according to LAA thrombus

\begin{tabular}{|c|c|c|c|c|}
\hline \multicolumn{2}{|c|}{$\begin{array}{ll}\text { Groups } \\
\text { Parameters }\end{array}$} & $\begin{array}{l}\text { Patients with } \\
\text { LAA thrombus } \\
(\mathbf{n}=5)\end{array}$ & $\begin{array}{l}\text { Patients without } \\
\text { LAA thrombus } \\
\quad(\mathbf{n}=\mathbf{2 5})\end{array}$ & P value \\
\hline \multirow{2}{*}{ Age } & Mean \pm SD & $67.60 \pm 5.03$ & $59.04 \pm 9.26$ & \multirow{2}{*}{0.057} \\
\hline & Range & $60-72$ & $38-73$ & \\
\hline \multirow{2}{*}{ Gender } & Male & $3(60 \%)$ & $18(72 \%)$ & \multirow{2}{*}{0.593} \\
\hline & Female & $2(40 \%)$ & $7(28 \%)$ & \\
\hline \multicolumn{2}{|c|}{ HTN } & $4(80 \%)$ & $22(88 \%)$ & 0.631 \\
\hline \multicolumn{2}{|c|}{$\mathrm{DM}$} & $3(60 \%)$ & $6(24 \%)$ & 0.109 \\
\hline \multicolumn{2}{|c|}{ Smoking } & $3(60 \%)$ & $16(64 \%)$ & 0.856 \\
\hline \multicolumn{2}{|c|}{ History of stroke/TIA } & $4(80 \%)$ & $1(4 \%)$ & $<0.001$ \\
\hline
\end{tabular}

According to basic characteristic of studied patients, there were no statistically significant difference in age $(\mathrm{P}$ value $0.057)$, height $(\mathrm{P}$ value 0.101$)$, weight $(\mathrm{P}$ value $=0.241)$ and $\mathrm{BMI}(\mathrm{P}$ value 0.064$)$, while AF duration (P value 0.002) and CHADS2VA2Sc score ( $\mathrm{P}$ value 0.007) had statistically significant difference (Table 5).

Table (5): Comparison of basic characteristic of studied patients according to LAA thrombus

\begin{tabular}{|c|c|c|c|}
\hline Groups & $\begin{array}{c}\text { Patients with LAA } \\
\text { thrombus } \\
(\mathbf{n = 5})\end{array}$ & $\begin{array}{c}\text { Patients without } \\
\text { LAA thrombus } \\
(\mathbf{n = 2 5})\end{array}$ & $\begin{array}{c}\text { P } \\
\text { value }\end{array}$ \\
\hline CHAameters & $5.0 \pm 1.87$ & $2.04 \pm 1.79$ & 0.002 \\
\hline Duration & $4.8 \pm 1.64$ & $2.16 \pm 1.46$ & 0.007 \\
\hline Hight & $176.6 \pm 3.58$ & $171.84 \pm 6.01$ & 0.101 \\
\hline Weight & $72.8 \pm 7.56$ & $77.68 \pm 8.45$ & 0.241 \\
\hline BMI & $23.35 \pm 2.5$ & $26.38 \pm 3.31$ & 0.064 \\
\hline
\end{tabular}


By analysis and comparison of laboratory findings of the studied patients, there were no statistically significant difference in creatinine ( $\mathrm{P}$ value 0.385$)$, INR ( $\mathrm{P}$ value 0.416$)$, and GFR ( $\mathrm{P}$ value 0.327) (Table 6).

Table (6): Comparison of laboratory findings of studied patients according to LAA thrombus

\begin{tabular}{|c|c|c|c|}
\hline Functions & $\begin{array}{c}\text { Patients with LAA } \\
\text { thrombus(n = 5) }\end{array}$ & $\begin{array}{c}\text { Patients without LAA } \\
\text { thrombus(n =25) }\end{array}$ & P value \\
\hline Creatinine & $1.4 \pm 0.3$ & $1.34 \pm 0.557$ & 0.385 \\
\hline INR & $1.2 \pm 0.265$ & $1.11 \pm .209$ & 0.406 \\
\hline GFR & $57.78 \pm 17.76$ & $73.33 \pm 33.73$ & 0.327 \\
\hline
\end{tabular}

Different several 2D TTE parameters were compared in both groups including LA diameter ( $\mathrm{P}$ value 0.008), LV EDD ( $\mathrm{P}$ value < 0.001), LV ESD ( $\mathrm{P}$ value < 0.001), LV EDV (P value 0.122), LV ESV $(\mathrm{P}$ value 0.085$)$ and $\mathrm{LV}$ EF (P value $0.085)$, LA length A4 (P value 0.108), LA area A4 (P value 0.005), LA volume A4 ( $\mathrm{P}$ value 0.001$)$, LA volume index A4 (P value 0.002$)$, LA length $\mathrm{A} 2$ ( $\mathrm{P}$ value $0.288)$, LA area A2(P value <0.001), LA volume A2 (P value 0.003), LA volume index A2 (P value 0.001), LA biplane volume ( $\mathrm{P}$ value 0.004), LA biplane volume index (P value 0.005), all parameters showed statistically significant difference between two groups $(\mathrm{P}$ value $<0.05)$ except LV EDV, LV ESV, EF, LA length A4, LA length A2 which showed no statistically significant difference $(\mathrm{P}$ value $>0.05$ ) (Table 7).

Table (7): Comparison of 2D TTE findings of studied patients according to LAA thrombus

\begin{tabular}{|c|c|c|c|}
\hline Functions & $\begin{array}{c}\text { Patients with } \\
\text { LAA thrombus } \\
(\mathbf{n = 5})\end{array}$ & $\begin{array}{c}\text { Patients without } \\
\text { LAA thrombus } \\
(\mathbf{n}=\mathbf{2 5})\end{array}$ & P value \\
\hline LA diameter $(\mathrm{mm})$ & $47.6 \pm 2.7$ & $41.5 \pm 4.56$ & 0.008 \\
\hline LV EDD $(\mathrm{mm})$ & $56 \pm 0.539$ & $52.1 \pm 0.448$ & $<0.001$ \\
\hline LV ESD $(\mathrm{mm})$ & $43.0 \pm 1.0$ & $34.7 \pm 0.583$ & $<0.001$ \\
\hline LV EDV $(\mathrm{ml})$ & $155.24 \pm 32.88$ & $131.46 \pm 24.4$ & 0.122 \\
\hline LV ESV $(\mathrm{ml})$ & $88.5 \pm 41.18$ & $51.82 \pm 20.66$ & 0.085 \\
\hline LV EF $(\%)$ & $45.92 \pm 17.89$ & $61.53 \pm 10.61$ & 0.085 \\
\hline LA length A4 & $61.6 \pm 5.9$ & $55.1 \pm 8.3$ & 0.108 \\
\hline LA area A4 & $31.72 \pm 4.53$ & $23.12 \pm 5.93$ & $<0.001$ \\
\hline LA volume A4 & $134.36 \pm 43.36$ & $72.82 \pm 33.34$ & 0.001 \\
\hline LA volume index A4 & $70.76 \pm 20.43$ & $38.11 \pm 17.18$ & 0.002 \\
\hline LA length A2 & $59.4 \pm 11.9$ & $54.2 \pm 9.41$ & 0.288 \\
\hline LA area A2 & $29.66 \pm 2.95$ & $23.52 \pm 4.72$ & $<0.001$ \\
\hline LA volume A2 & $116.64 \pm 15.45$ & $77.81 \pm 28.77$ & 0.003 \\
\hline LA volume index A2 & $62.66 \pm 10.46$ & $38.63 \pm 16.85$ & 0.001 \\
\hline LA biplane volume & $125.54 \pm 23.82$ & $78.29 \pm 35.73$ & 0.004 \\
\hline LA biplane volume index & $66.32 \pm 10.46$ & $41 \pm 19.53$ & 0.005 \\
\hline
\end{tabular}




\section{DISCUSSION}

Enlargement of left atrium (LA) has been established as a prognostic marker for adverse $\mathrm{CV}$ outcomes such as atrial fibrillation, stroke, congestive heart failure, and cardiovascular death. This study aimed to evaluate the accuracy of LA volume index to predict transesophageal echocardiographic (TEE) LAA thrombus .

In comparison to our results, some previous studies found that the higher LA volume and/or lower left ventricular ejection fraction (LVEF) and the ratio of LVEF to LA volume index (LAVI) might be markers of LA appendage thrombus in patients with non valvular AF and $15.6 \%$ of patients had LAA thrombus and found that CHADSVASc scores was > 1, with mean 2.5 in patients with LA appendage thrombus Vs. 1.9 in patients without LAA thrombus with (p .04), and CHADSVASc score had significant predictors of LA appendage thrombus formation (Ayirala et al., 2011).

Our study agreed with Doukky et al. (2013) who had done external validation of Ayirala's study in reporting that $8.8 \%$ of patients had LAA thrombus, and also had a higher mean CHADS2 score, lower mean LVEF, higher mean LAVI, and higher prevalence of cardiac failure. LA appendage thrombus was not seen in patients with LA volume indexes $<28$ $\mathrm{mL} / \mathrm{m} \mathrm{2}$. The ratio of LVEF to LA volume index 1.5 produced $100 \%$ sensitivity for the presence of LA appendage thrombus.

Jordan and his Colleagues (2019) found that LA volume index was greater in patients with cardioembolic stroke than non cardioembolic stroke and volume indexed is superior metric of LA dimension to predict cardiovascular outcomes.

Faustino et al. (2014) found that indexed measurements of LA area 4 chambers (4C), LA volumes had moderate to high discriminatory power in the prediction of LAA thrombus, LAA low flow velocities and dense SEC without significant differences between them. Indexed LA area 4C was an independent predictor of all TEE endpoints. For LAA thrombus, indexed biplane volume was a predictor of TEE surrogate markers of stroke and aimed to evaluate the accuracy of LA volume index and LA size to identify TEE markers of thromboembolic risk in patients with $\mathrm{AF}$.

Kaniz and his Colleagues (2010) found that patients with increased LA volume index were older had more cardiovascular risk factors, and were more likely to have more than 1 risk factor than patients with normal LA volume index in patients with first ever ischemic stroke.

Jaroch et al. (2016) conducted a retrospective analysis of demographic, clinical, laboratory, echocardiographic and medication data of patients with persistent AF, who underwent TEE before electrical cardioversion. He found that left atrial diameter of $\geq 51 \mathrm{~mm}$ was an independent predictor of LAA thrombus.

In our study, we found that CHADS2VA2Sc score had significant difference in both groups. This study was concordant with other studies that found patients with LAA thrombus and other thromboembolic risk markers had high CHADSVASc scores. This can be explained by high prevalence of thromboembolic risk factors including older age, diabetes, previous stroke or 
TIA, vascular diseases and heart failure.These results were concordant with those reported by previous studies (Doukky et al., 2013 and Floria et al., 2013).

Cross-sectional study was done on patients with non-valvular AF underwent TEE. The results were that the addition of LA area and LVEF to the CHA2DS2VASc scores increased their discriminative capability with regard to LA appendage thrombus, dense SEC, and low LAA flow velocities (Providência et al., 2012).

In this study, the presence of LAA thrombus was associated with longer AF duration, These results were in agreement with Faustino et al. (2014) who found that patients with paroxysmal AF had no LAA thrombus, while patients with longer AF duration (persistent AF) had LAA thrombus.

\section{CONCLUSION}

LA volume index was suitable to predict LAA thrombus in patients with non-valvular AF.

\section{REFERENCES}

1. Ayirala S, Kumar S, O'Sulivan DM and Silverman DI. (2011): Echocardio- graphic predictors of left atrial appendage thrombus formation. J Am Soc Echocardiogr., 24:499505.

2. Doukky R, Khandelwal A, Garcia-Sayan E and Gage H. (2013): External validation of a novel transthoracic echocardiographic tool in predicting left atrial appendage thrombus formation in patients with nonvalvular atrial fibrillation. Eur Heart J., 14(9):876-81.

3. Faustino A, Provide^ncia R, Barra S, Paiva L, Trigo A and Botelho A. (2014): Which method of left atrium size quantification is the most accurate to recognize thromboembolic risk in patients with non-valvular atrial fibrillation? Cardiovascu Ultrasound, 12:2835 .

4. Floria M, De Roy L, Xhaet O, Blommaert D, Jamart J and Gerard M. (2013): Predictive value of thromboembolic risk scores before an atrial fibrillation ablation procedure. J Cardiovascu Electrophysiol., 24(2):139-45.

5. Garnock-Jones KP and Curran MP. (2010): Regadenoson. Am J Cardiovasc Drugs, 10:65-71.

6. Jaroch J, Kamińska-Kegel A, Brzezińska B, Kruszyńska E, Bociąga $Z$, Dudek $K$ and Loboz-Grudzień K. (2016): Predictors of left atrial appendage thrombogenic milieu in patients subjected to transesophageal echocardiography prior to cardioversion of persistent atrial fibrillation. Pol Arch Med Wewn., 126 (1-2): 25-31.

7. Jordan K, Yaghi S, Poppas A, Chang A, Grory B, Cutting S, Burton $T$ and Jayaraman M. (2019): Left Atrial Volume Index Is Associated With Cardioembolic Stroke and Atrial Fibrillation Detection After Embolic Stroke of Undetermined Source. Stroke, 50:1997-2001.

8. Kaniz F, Bailey K, George P, Meissner I, Osranek $M$ and Seward J. (2010): Increased Left Atrial Volume Index: Potent Biomarker for First-Ever Ischemic Stroke. Mayo Clinic Proceedings, 83; 1107-1114.

9. Lip GY, Nieuwlaat R, Pisters R, Lane DA and Crijns HJ. (2010): Refining clinical risk stratification for predicting stroke and thromboembolism in atrial fibrillation using a novel risk factor-based approach: the euro heart survey on atrial fibrillation. Chest, 137:263-72.

10. Providência R, Trigo J and Paiva L. (2011): The role of echocardiography in thromboembolic risk assessment of patients with non valvular atrial fibrillation. J Am Soc Echocardiogr., 26:801-12. 
در اسة العلاقه بين الحجم النسبي للأذين الأيسر عن طريق

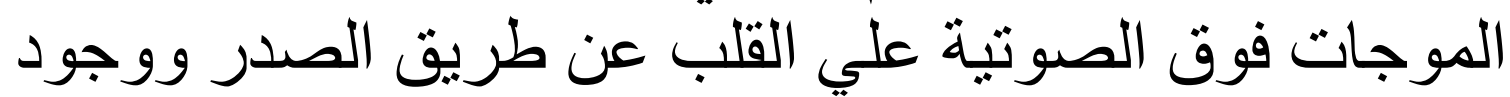

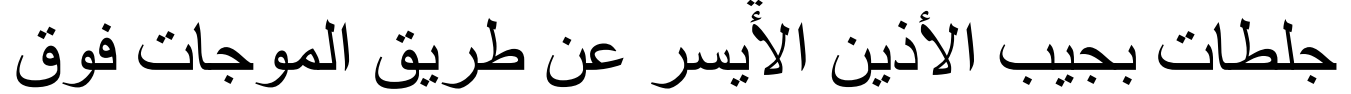
الصوتية بالمنظار علي القلب في مرضي الرفرفة الإني الأذينية الغير صمامبة الفية

محمد ماجد عبدالعاطي منصور، محمد سامي عبدالسميع، سامي حسن نوح قسم القلب والأوعية الدموية، كلية الطب، جامعة الأزهر

E-mail: $\underline{\text { drmohamedmaged2020@gmail.com }}$

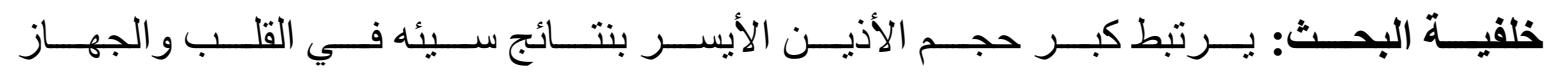

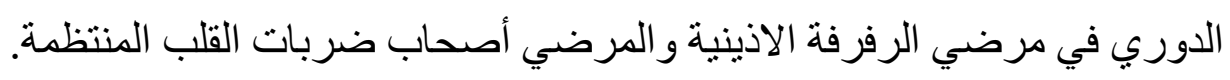

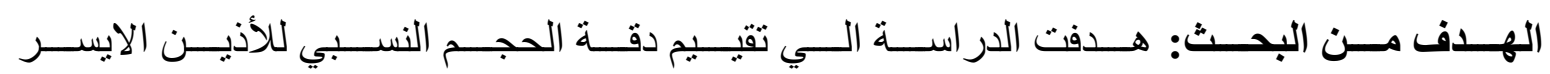

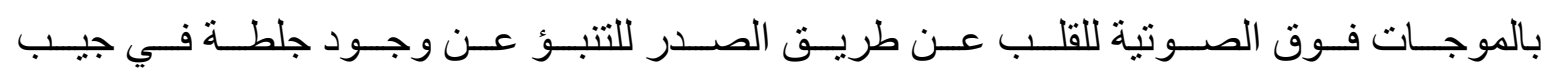

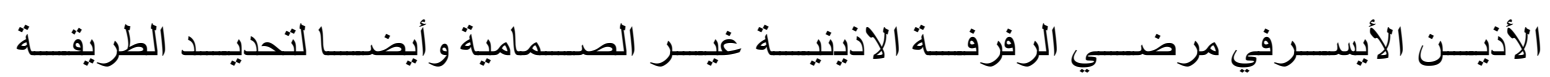
الأمثل لتقييم حجم الأذين الأيسر.

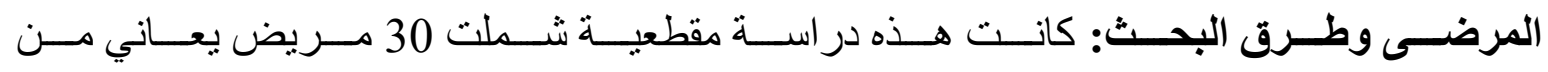

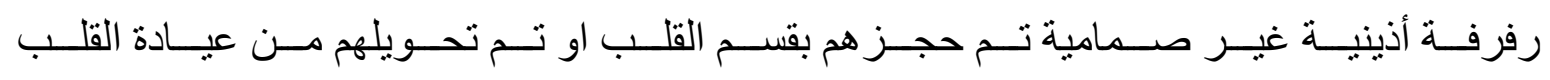

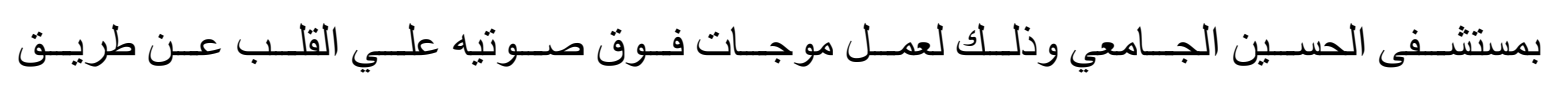

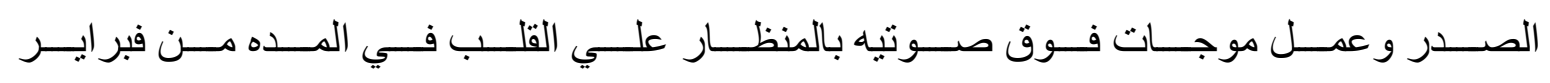

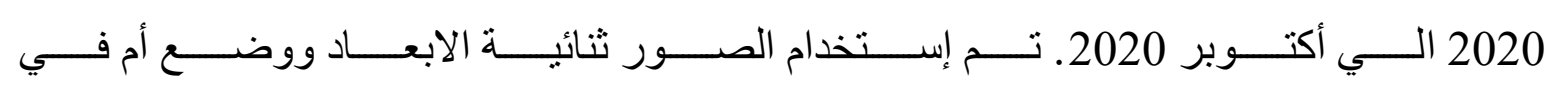

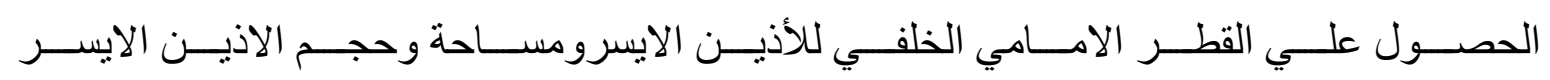

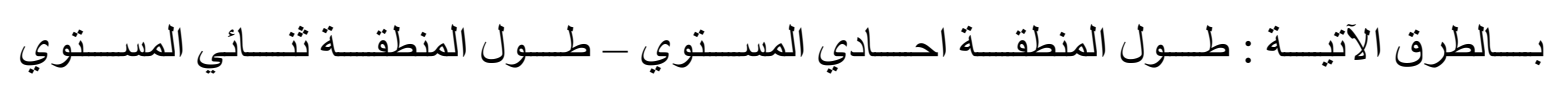

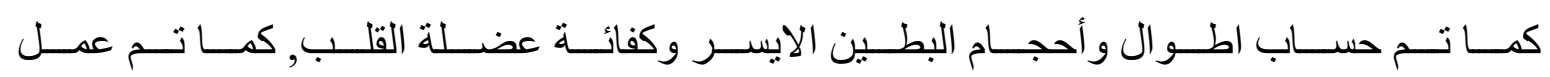

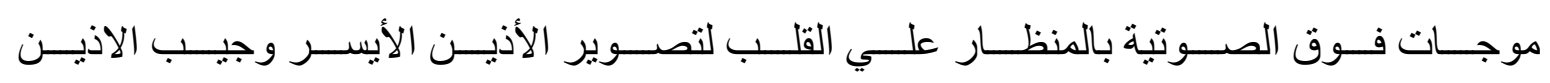

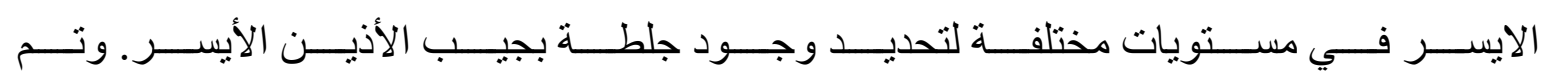

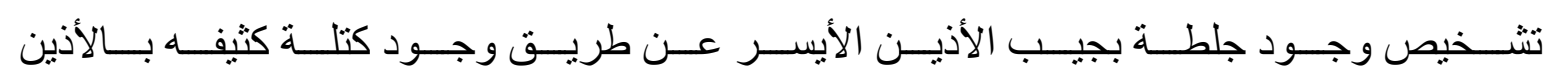
الأيسر أو بجيب الأذين الأيسر. 


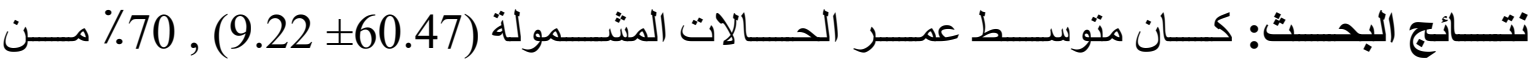

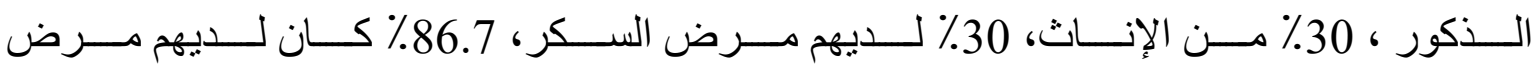

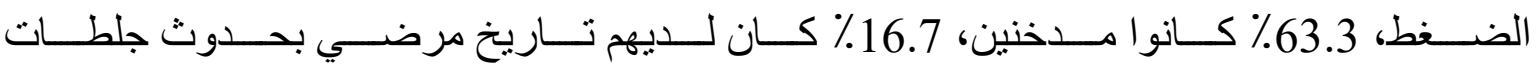

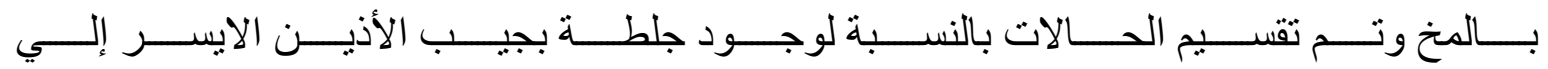

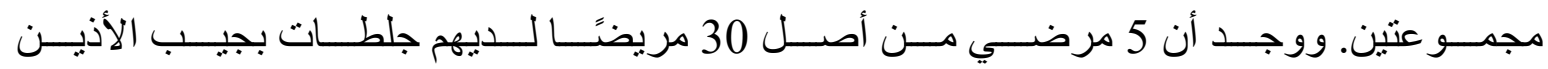

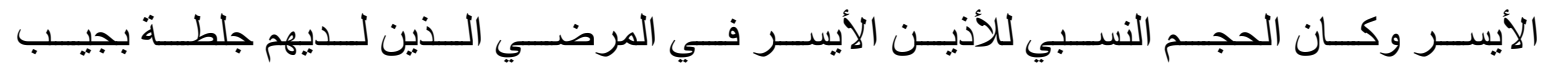
الأذيــن الأيســر فــي وضـــع المنظـــر ربـــاعي الثــرفات بقمـــة القلــب (20.43+70.76)

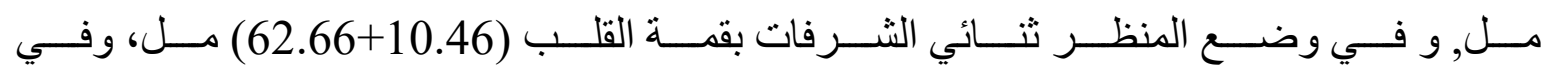

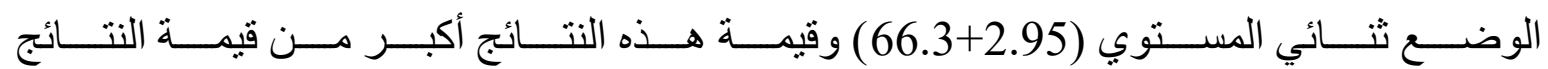
للمرضي الذين ليس لديهم جلطة بجيب الأذين الأيسر.

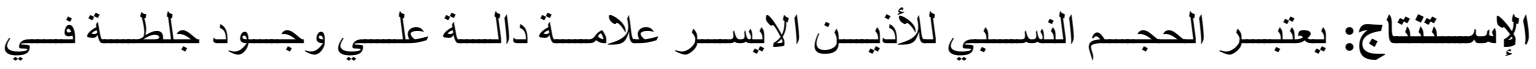
جيب الأذين الأيسر في مرضي الرفرفة الاذينية الغير صمامية.

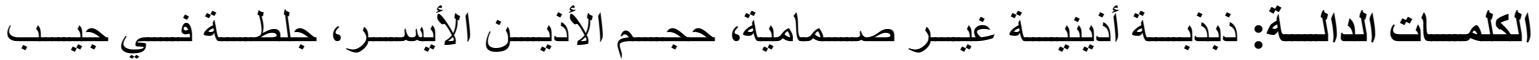

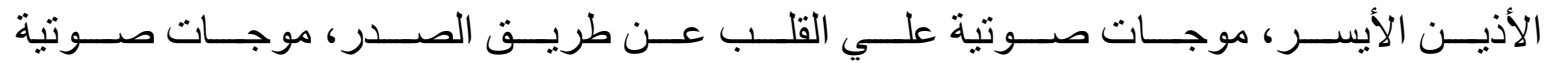
علي القلب بالمنظار. 